\title{
Teletandem e ensino de Português Língua Estrangeira (PLE): reflexões de docentes vinculados ao ensino público paulista
}

\author{
Christiane Moisés MARTINS ${ }^{1}$ \\ Universidade de Brasília \\ Universidade Paulista Júlio de Mesquita Filho (UNESP - São José do Rio \\ Preto) \\ jr.anne@gmail.com \\ Ludmila Belotti Andreu FUNO² \\ Universidade Paulista Júlio de Mesquita Filho (UNESP - São José do Rio \\ Preto) \\ lbandreu@hotmail.com
}

\section{Resumo}

A comunicação digital na era da web 2.0 vem transformando as práticas educacionais, exigindo do professor o desenvolvimento de outros saberes paralelos àqueles da sala de aula presencial. Este artigo trata das reflexões emergentes sobre o ensino do Português como Língua Estrangeira (PLE) em ambiente midiático e na modalidade in-tandem. O objetivo central é explicitar as reflexões de professores em formação como usuários de ferramentas tecnológicas, as diversas manifestações linguísticas em contextos digitais e o questionamento sobre a viabilidade de experiências de aprendizagem diferenciada, interativa e direcionada na área de PLE.

Palavras-chave: contextos digitais; teletandem; Português Língua Estrangeira.

1 Professora do Programa de Ensino e Pesquisa para Falantes de Outras Línguas (PEPPFOL) do Departamento de Línguas Estrangeiras e Tradução (LET) da UnB e doutoranda em Estudos Línguísticos pelo Instituto de Biociências, Letras e Ciências Exatas da UNESP - São José do Rio Preto). Pesquisadora do projeto Teletandem Brasil - Línguas Estrangeiras para todos (www.teletandembrasil.org).

2 Doutoranda em Estudos Línguísticos pelo Instituto de Biociências, Letras e Ciências Exatas da UNESP - São José do Rio Preto). Pesquisadora do projeto Teletandem Brasil - Línguas Estrangeiras para todos (www.teletandembrasil.org). 


\begin{abstract}
Digital communication concerning the web 2.0 modality has been transforming educational practices since it demands the development of additional knowledge besides the face-to-face classroom mode. This article concerns teacher's reflections in relation to Portuguese as a Foreign Language (PFL) in virtual environments and in intandem contexts. The focus surrounds making explicit the reflections of in-service teachers as users of technological tools, with the consideration of linguistic issues that emerge in a virtual context as well as the possibilities of a differentiated interactive learning style regarding PFL.
\end{abstract}

Keywords: digital environment; teletandem; Portuguese as a Foreign Language.

\title{
1. Um breve panorama do Projeto Teletandem Brasil
}

As oportunidades de romper as fronteiras da tradicional sala de aula de línguas estrangeiras emergiram de maneira contundente com o desenvolvimento da rede mundial de comunicação (world wide web). A partir do advento da disponibilização da web, o acesso às culturas e aos diferentes idiomas e linguagens, por exemplo, passa a acontecer de variadas maneiras. Esse desenvolvimento transformou o computador em um instrumento dotado de potencialidade dinâmica e interativa no âmbito da educação tanto presencial como a distância. Como atestado em vários estudos, ${ }^{3}$ os ambientes virtuais utilizados para subsídio da aprendizagem on-line proporcionam contextos favoráveis ao desenvolvimento da autonomia ou do gerenciamento do próprio processo de aprendizagem e de intercâmbios socioculturais.

Alinhados a essas premissas, situam-se os projetos de aprendizagem de línguas in-tandem, dentre outros projetos telecolaborativos (BELZ, 2003; O'DOWD, 2005) nos quais pares de aprendentes nativos ou competentes de uma LE ensinam um ao outro a sua língua visando à interação social, ao

3 Ver, por exemplo, Kern (2006) e Thorne e Payne (2005), para uma revisão da literatura. 
diálogo, ao debate e, juntamente com o benefício linguístico, à possibilidade de desenvolvimento da referida competência comunicativa intercultural (BYRAM, 1997), ou ainda, à possibilidade de uma vivência transcultural (WELSCH, 1994).

Nesse cenário está inserido o projeto Teletandem Brasil: línguas estrangeiras para todos (TTB), ${ }^{4}$ cujos eixos de pesquisa se concentram no desenvolvimento do professor em ambiente midiático multimodal no e para o contexto de teletandem nos processos interativos de aprendizagem e nas ferramentas de comunicação que viabilizam a interatividade (VASSALLO; TELLES, 2009). Tais eixos fundamentamse pedagógica e metodologicamente segundo os estudos de CALLT $^{5}$ e de $\mathrm{CMC}^{6}$ relacionados intrinsicamente à area da Linguística Aplicada. Define-se, assim, teletandem como um contexto de aprendizagem que: (a) viabiliza oportunidades de socialização e de individualização; (b) está baseado no conceito de autonomia (co)construída, envolvento a tomada de decisões não em isolamento, mas em conjunto com o outro; (c) compartilha e alterna os papéis de quem retém o conhecimento; (d) exige uma adequação (e por que não dizer metamorfose) do professor para o processo da aprendizagem em ambiente midiático (VASSALLO; TELLES, 2006; TELLES, 2009).

Nesse contexto virtual de aprendizagem de línguas estrangeiras (doravante LE) recíproco, autônomo e colaborativo a distância, são usados aplicativos da web 2.0, definidos como sistemas que permitem compartilhamento de informações, caracterizados pela possibilidade de participação e intervenção dos sujeitos e verdadeiros catalizadores dos processos da "arquitetura de interação" que ocorrem por meio das atividades colaborativas em múltiplos ambientes e comunidades virtuais (O'REILLY, 2007).

Assim sendo, as ferramentas da web 2.0 utilizadas são as de mensagem instantânea com áudio e imagens de webcam (Skype, Windows

\footnotetext{
4 Para maiores informações acerca desse projeto, acesse <www.teletandembrasil.org>.

5 Computer Assisted Language Learning and Teaching; Ensino/Aprendizagem de Línguas Assistidos por Computador.

6 Computer mediated communication; comunicação mediada pelo computador.
} 
Live Messenger e OoVoo, por exemplo) munidas de aplicativos para anotações síncronas Talk \& Write, que funciona acompanhado do Skype. (VASSALLO; TELLES, 2006).

$\mathrm{O}$ uso desses aplicativos em situação de teletandem constitui um ambiente virtual síncrono propício ao ensino e à aprendizagem de línguas, uma vez que os recursos de áudio, leitura, escrita e imagem dos aplicativos em questão permitem a utilização e, consequentemente, o desenvolvimento das cinco competências descritas no Quadro Europeu Comum de Referência para as Línguas (QECR), ${ }^{7}$ desenvolvido pelo Conselho da Europa, que são: compreensão oral, compreensão escrita, produção oral, produção escrita e interação e que estão abarcadas no (a) componente linguístico (os conhecimentos e capacidades lexicais, fonológicas e sintáticas), (b) sociolinguístico (o contexto sociocultural do uso da língua, como por exemplo, as regras de boa educação, as normas que regem as relações entre gerações, sexos, classes e grupos sociais, etc.) e (c) pragmático (o domínio do discurso, da coesão e da coerência, a identificação de tipos e formas de textos, a ironia, a paródia, a criação de um argumento interacionais).

Além disso, os interagentes de teletandem modalidade contam com o auxílio de professores formadores ou linguistas aplicados, que exercem o papel de mediadores do processo interativo on-line.

\section{O contexto do estudo}

Com o intuito de possibilitar a inserção do teletandem na rede pública de educação do Estado de São Paulo, foi promovido um curso semipresencial de formação continuada para um grupo de professores brasileiros de espanhol como língua estrangeira, ligados aos $\mathrm{CELs}^{8}$ pertencentes a duas Diretorias de Ensino (DEs) distintas do interior paulista. ${ }^{9}$

7 Disponível na íntegra em: <http://www.dgidc.min-edu.pt/linguas_estrangeiras/Paginas/QECR.aspx >.

8 Os Centros de Estudo de Línguas (CEL) são fruto de um programa da Secretaria da Educação do Estado de São Paulo (SEE-SP), que oferece ensino de línguas estrangeiras gratuito para alunos da rede pública estadual. Mais informações: <http://nev.incubadora.fapesp.br/portal/educacao/idiomas/cel>.

9 Deste curso participaram sob a condição de convidados professores uruguaios de português como língua estrangeira que interagiram em regime de teletandem com os colaboradores brasileiros deste estudo. 
O referido curso de formação continuada transcorreu durante o segundo semestre de 2009 e intitulou-se Formação do Professor para o Ensino/ Aprendizagem de Línguas Estrangeiras em Tandem. O objetivo principal do curso em questão era proporcionar a reflexão de seus participantes acerca da fundamentação, das práticas e das possibilidades de inserção do teletandem em contexto público de ensino por meio tanto da experiência de aprimoramento de suas línguas estrangeiras em ambiente midiático quanto da discussão e do debate acerca da literatura que se tem publicado sobre teletandem nos últimos anos.

Para dar suporte aos participantes do curso supracitado, sistematizar e desenvolver o trabalho no qual este artigo está fundamentado, fez-se uso da plataforma TelEduc. ${ }^{10}$ As ferramentas pedagógicas do TelEduc, listadas a seguir, serviram como instrumentos de coleta de dados para este estudo: (a) perfis, (b) fóruns, (c) bate-papos, (d) autoavaliações (todos postados nos portfólios da plataforma); transcrições das gravações feitas durante os (e) encontros presenciais; e histórias sob o formato de (f) narrativas de experiência vivida.

Com base nesses dados, este estudo tece reflexões textuais acerca das representações sociais (doravante $\mathrm{RS}$ ) dos participantes de pesquisa que interagiram tanto presencialmente quanto por meio dos mecanismos de comunicação on-line utilizados (síncronos e assíncronos), debatendo, questionando, refutando hipóteses sobre e em contexto teletandem. Ressaltamos que para esses colaboradores de pesquisa o teletandem era algo ainda incomum, uma prática que há pouco começava a ser experimentada e precisava ser entendida assim como as experiências de ensino em Português Língua Estrangeira (doravante PLE), que também eram novidade para esses participantes.

10 TelEduc: plataforma virtual que subsidia a criação e a gestão de cursos on-line. Para mais detalhes, acesse: <http://www.teleduc.org.br/>. 


\section{Metodologia}

Neste artigo, trazemos um recorte dos estudos que desenvolvemos ao longo dos anos de 2009 e de 2010 e apresentamos dados de oito participantes focais, dentre os 13 colaboradores, cujos nomes fictícios são: Débora, Madalena, Ana, Gesebel, Carla e Penélope (participantes brasileiras), Mariella e Juan (participantes uruguaios). A escolha pelo referido recorte justifica-se pelo fato de que dentre os envolvidos no contexto deste estudo somente esses oito colaboradores explicitaram inquietações referentes ao teletandem e, concomitantemente, ao ensino de PLE.

Ressaltamos que os dados foram coletados em um contexto de formação continuada para docentes brasileiros de espanhol/LE que interagiram em regime de teletandem com parceiros uruguaios, que, por sua vez, eram professores de PLE em seu país. Os cenários que subsidiaram a coleta de dados, como já explicitamos, foram: (a) a sala para os encontros presenciais, onde foram realizadas atividades de instrução técnica para uso de softwares de interação e comunicação, videoconferências e atividades diversas como debates e mediação; e, (b) o TelEduc, plataforma virtual que subsidiou parte das atividades do referido curso. A coleta, portanto, deu-se a partir (a) da gravação dos encontros presenciais e (b) das ferramentas pedagógicas disponibilizadas na plataforma TelEduc como anteriormente descrito.

Com base na sistematização dos dados em corpus de pesquisa, buscouse tratá-los de forma interpretativa, seguindo a metodologia hermenêutica fenomenológica de van Manen (1990). Conforme tal abordagem, a teorização e a prática textual da escrita estão intimamente ligadas e emergem do estudo dos dados, não podendo ocorrer separadamente (VAN MANEN, 1990, p. 7).

Assim, após dispor (a) da transcrição das discussões feitas pelos participantes de pesquisa durante os encontros presenciais, (b) da coleta das asserções destes (suas construções de significados) postadas na plataforma TelEduc e (c) da coleta dos relatos de experiência vivida, buscamos a verificação dos temas, ou seja, a identificação das recorrências ou motifs 
(VAN MANEN,1990, p. 78), seguindo-se à interpretação das contribuições dos participantes de pesquisa em relação ao ensino de PLE.

A abordagem hermenêutica fenomenológica interpretativista, conforme apresentada por van Manen (1990), está intimamente ligada a uma prática reflexiva (do pesquisador e, em alguns casos, do participante, ou ambos) sobre o texto apresentado pelo participante da pesquisa quando fala ou escreve acerca de sua experiência. A intenção de tal prática é elucidar as estruturas significativas das experiências humanas, conforme tais experiências foram vividas.

Tal abordagem encontra-se em sintonia com a intenção deste trabalho, que é elucidar as RSs dos participantes de pesquisa acerca de suas experiências com o ensino de PLE em teletandem. Isso porque as RSs emergem das tentativas de se compreender ou construir significados a respeito de algo (que pode ser incomum, provocador, etc.), objetivando-se por meio da comunicação e construindo uma realidade social (MOSCOVICI, 2007). Esta abordagem metodológica busca compreender: (a) como a significação é conferida ao objeto representado; (b) como a representação é utilizada como sistema de interpretação do mundo social e instrumentaliza a conduta; (c) como se dá sua integração em um sistema de recepção e como influencia e é influenciada pelos elementos que aí se encontram (JODELET, 1990), alinhando-se a um estudo hermenêutico fenomenológico que intenciona tecer uma reflexão textual acerca da experiência vivida em sua singularidade (do participante que a relata) no contexto real das interações humanas (VAN MANEN, 1990, p. 7).

Tomamos as representações sociais neste estudo de caso como fenômenos que podem ser observados, descritos e interpretados, como elementos simbólicos capazes de perdurar e influenciar o modo de viver de gerações e de serem, também, modificados pelos indivíduos (MOSCOVICI, 2007), que podem trazer luz sobre as reflexões a respeito do ensino de PLE que emergiram de uma primeira tentativa de inserção do teletandem em seguimentos vinculados à educação básica pública do Estado de São Paulo. 


\section{Análise dos dados}

Os interagentes de teletandem que contribuíram para este estudo demonstraram compreender que a interação com seus parceiros trouxe em seu bojo especificidades no que tange ao ensino de PLE, como aparece no excerto a seguir, extraído dos comentários da colaboradora Madalena:

[...] é claro que a experiência que a gente viveu quando nós começamos a participar do curso nós já sabíamos que seriam professores de língua portuguesa do Uruguai... Então, você já chega pra: pra prática do teletandem já sabendo que o parceiro vai ter o conhecimento da/do português da língua então é: diferentemente duma situação onde nós como professores de espanhol... duma situação que você vai é... agir como professor de uma pessoa que não sabe NADA de português, então já passei por uma experiência de lecionar pro mexicano que não sabia nada de português então é uma situação muito diferente (Madalena - transcrição de gravação feita em encontro presencial).

O relato de Madalena mostra que, mesmo antes do curso de formação continuada, essa participante já teve a experiência de ensinar PLE para um falante de espanhol/LM. Acentua também o fato de que a parceria se deu entre duas pessoas formadas para o ensino de línguas estrangeiras e o bom conhecimento da língua portuguesa por parte do parceiro uruguaio de teletandem facilitou para Madalena o ensino de PLE.

Ana também comenta suas percepções acerca das interações de teletandem em que teve de ensinar PLE. Segundo a participante,

[...] é assim a gente percebeu que você pode tratar de dois aspectos o cultural e o linguístico ... o cultural realmente assim no meu caso havia coisas que no/no relato dela... perguntas que eu fazia sobre questões de alimentação... de hábitos de alimentação e que com o relato dela eu fui perceber o quanto havia é de... eu é... de coisas que eu não havia me dado conta de como o brasileiro põe uma mesa muito farta né e sempre muito: com muitas cores com muita variedade e o estrangeiro não e 
a gente estranha isso... [...] que eu senti uma certa facilidade para trabalhar com questões linguísticas com ela né ensinar o português por que impressão que eu tenho é que sempre que a gente tá na sala de aula nós sempre estamos comparando... o: português com o espanhol eu acho que isso foi uma uma característica particular assim... no caso desse curso... (Ana transcrição de gravação feita em encontro presencial).

O relato de Ana evidencia a sua percepção de que o ensino de PLE tem duas características majoritárias: a linguística e a cultural. $\mathrm{O}$ aspecto cultural é apresentado como mais complexo, afinal a professora demonstra ter encarado situações de estranhamento da própria cultura no contato com o estrangeiro.

Observamos ao longo do curso ministrado que a questão cultural no ensino de PLE é temática de destaque, principalmente no que diz respeito ao fato de que "a língua reflete a identidade nacional pela identidade linguística, na medida em que é um filtro através do qual se vê, se pensa e se exprime" (ORTIZ; SANTOS, 2010, p. 222).

A fala a seguir ilustra um aspecto dessa questão identitária. Para Helena, defrontar-se com o ensino de PLE foi "uma descoberta”, algo inesperado que a fez pensar em como, mesmo sendo professora de Espanhol/Língua Estrangeira, é diferente a reflexão que se faz ao ensinar PLE.

Bom... vou começar então com a minha experiência então eu achei ah: foi assim uma descoberta nova... realmente, a gente não pensa na nossa língua como língua estrangeira e aquilo é um grande dificultador... você... às vezes o parceiro pergunta uma coisa que você num... não tá acostumado a pensar sobre aquilo na sua língua... num aspecto cultural do seu país você não reflete sobre aquilo você não percebe que... que é diferente e aí você começa a criar um conhecimento a partir do outro... daquela dúvida... questionamentos de como você utiliza a língua e às vezes você não se dá conta daquilo porque VOCÊ UTILIZA, você não pensa para utilizar, por que é a sua língua materna... então assim foi uma grande dificuldade em alguns momentos (Helena- transcrição de gravação feita em encontro presencial). 
Complementando a questão identidade e cultura, outro ponto recorrente nesse estudo diz respeito ao conflito estabelecido pela abordagem de ensino dos participantes, exemplificada pela fala de Gesebel acerca de sua experiência com seu par interagente ao longo de sessões de teletandem:

[...] e aí, como no Uruguai a questão é o voseo, né... e eu me vi assim ... eu não quis usar o voseo... e ele falou vamos usar ou não vamos usar, né: você quer ? ...e aí eu me coloque, né... bom, ...eu vou usar o voseo e aí eu vou ensinar isso pros meus alunos e eu vou restringir o uso da língua, né ...vou deixar numa região... Eu quero aprender, mas pra mim... e aí a gente brinca, né... ele fala que enquanto eu uso o espanhol da Espanha então ele vai usar o português de Portugal... e aí a gente entra num conflito, porque eu não quero ouvir o português de Portugal, né? (Gesebel - transcrição de gravação feita em encontro presencial).

No trecho supracitado, Gesebel fala sobre os estranhamentos engendrados em sua parceria pelo contato com a variante rioplatense de espanhol. Dá como um dos exemplos o uso do voseo, ${ }^{11}$ como desencadeador desse estranhamento. Em seguida, expõe os conflitos suscitados entre essa participante de pesquisa e seu parceiro de teletandem, uma vez que o que Gesebel tinha a oferecer para seu par interagente era também uma variante da língua portuguesa (a variante brasileira, do interior paulista). Percebemos aqui o início de uma necessária negociação relativa às culturas-identidades envolvidas nessa troca linguística. Christine Revuz, psicanalista francesa, ilustra bem essa "desestabilização" entre a identidade da língua materna e da estrangeira ao afirmar que:

A aprendizagem de línguas estrangeiras esbarra na dificuldade que há para cada um de nós, não somente de aceitar a diferença, mas de explorá-la, de fazê-la sua, admitindo a possibilidade de despertar os jogos complexos de sua própria diferença interna, da não coincidência de si consigo, de si com os outros, de aquilo que se diz com aquilo que se desejaria dizer (REVUZ, 1998, p. 230).

11 Variante uruguaia para se referir à segunda pessoa do singular. 
A procura pelo entendimento provocará uma reflexão das diferentes culturas e identidades em questão como veremos no relato abaixo, da colaboradora Gesebel:

[...] e aí hoje inclusive entrou nessa questão... ah: onde você ta... estoy in el salón... NO. No estás en la España para estar en el salón (risos) estás em um living... e aí, bom... Então a gente vai se deparando com um vocabulário novo e que... que às vezes eu sinto um certo receio em adquirir porque depois eu não consi... [eu tenho medo de até que ponto eu posso usar esse vocabulário no ensino, né ?Por que ele é restrito... e aí se eu adquiro e passo a usá-lo e: o meu aluno? Ele vai estar pronto para usá-lo em que situação?... né? Por que a gente pensa que ensina a língua standard a língua padrão pra depois adquirir essas pequenas diferenças e é sempre a experiência, essa experiência do teletandem é pra mim quanto para ele (o interagente uruguaio), mas em primeiro, enquanto professora, enquanto formadora? A gente se coloca lá no (longe) né? ... e em que momento eu vou usar (Gesebel - transcrição de gravação feita em encontro presencial).

Duas coisas chamam a atenção, nos trechos de Gesebel supracitados: a primeira delas é a maneira como essa participante de pesquisa representa a variante uruguaia (rioplatense) do espanhol com a qual teve contato por meio das sessões de teletandem. A variante em questão é considerada como tendo um vocabulário "restrito", não pertencente ao paradigma que compreende aquilo que, para Gesebel, seria o espanhol standard ou "padrão". A outra é a maneira como essa participante de pesquisa e seu par interagente se posicionam mediante as variantes daqueles que foram os colonizadores de suas nações, ou seja, Gesebel, participante de pesquisa brasileira, demonstra rejeição pela variante europeia da língua portuguesa, ao passo que seu par interagente, um uruguaio, rejeita a variante madrilenha do espanhol que fala. ${ }^{12}$

12 Por limitação de espaço, este artigo não abordará em profundidade as questões referentes ao espanhol rioplatense, bem como as questões linguísticas concernentes ao "português uruguaio", às escolas plurilíngues e às escolas bilíngues de fronteira. Para aprofundar este assunto, ver Geymont et al. (2007), Carvalho, A. (2003; 2008) e Souza (2010). 
Essa postura adotada por Gesebel (de rejeitar a variante peninsular do português e "exaltar" a variante peninsular do espanhol) resulta em "conflito" a partir do qual poderia se dar o sucesso ou insucesso do processo de aprendizagem em teletandem. Tal confronto deve ser tratado com cautela em situação de mediação da aprendizagem, sobretudo caso emerja dele manifestações de "estigma”, ou seja, "a situação do indivíduo que está inabilitado para aceitação social plena” (GOFFMAN, 1988, p. 7).

Ao longo do curso de formação continuada, essa não foi a primeira vez que um dos envolvidos demonstrou preocupação com a variante uruguaia de espanhol, embora tenha havido somente um registro e em tom de "brincadeira" sobre o uso da variante europeia em detrimento da variante brasileira. Como podemos observar em um registro do fórum intitulado Minhas Experiências de Teletandem, no qual se propunha a discutir a maneira como correções eram feitas e feedbacks eram oferecidos, Débora, outra participante deste estudo, também demonstrou desprestigiála postando:

Ainda não nos corrigimos. Somente conversamos e trocamos informações em espanhol. Observei que sem eu perceber comecei a usar o voseo no lugar do tú. Mas logo que me dei conta me corrigi sozinha, não por achar que estava errado, mas sim porque o meu espanhol é o da Espanha e dele eu não abro mão (Débora transcrição de gravação feita em encontro presencial).

Essa recorrência leva-nos a observar que a interação de teletandem oferece oportunidades para que se problematize a questão de identidade do espaço de enunciação dos interagentes e a percepção equivocada de que se exista em um idioma uma variante "melhor" que as outras (ver FAIRCLOUGH, 1992, sobre conscientização crítica da linguagem ${ }^{13}$ ).

Tal percepção sobre a variante vista como sendo a de maior prestígio foi evidenciada pelos participantes uruguaios. Em uma sessão de bate-papo, o participante Juan afirmou que "a maioria tem formação ibérica, até porque

13 Critical language awareness. 
a maioria dos professores universitários tem essa formação... a questão é não desenvolver preconceito em relação a alguma variante".

Observamos, entretanto, que à medida que a interação do grupo progredia, houve, sem dúvida, acréscimos e modificações das representações iniciais sobre as questões referentes às variantes de língua e língua/cultura veiculadas durante os debates e sessões de bate-papo.

Em um encontro presencial debateu-se a questão da variante dentre outros aspectos do ensino de LE. Depois disso, pediu-se que os docentes registrassem suas reflexões nos portfolio dos quais identificamos algumas representações dos participantes em relação ao PLE e à relação cultura/ língua:

a) Não se discute muito sobre a variante portuguesa; variante "preferida" é a do Brasil por causa do "jeito, pelo tipo do brasileiro, um povo alegre":

"eles (os estrangeiros) parecem gostar mais do Brasil - aqui nós somos abertos, acolhedores..." (Gesebel - trecho de postagem em portfólio virtual).

b) Os docentes passaram a pensar e a refletir sobre sua própria língua/ cultura, pois ora são instigados a pesquisar sobre sua própria cultura/língua ora são questionados sobre a história de sua nação:

Encarnación me indagou sobre o nome oficial do Brasil: República Federativa do Brasil, pedindo que eu explicasse: República (forma de governo 'do povo para o povo' com representação política do presidente - escolhido pelo povo) Federativa (composto por diversos territórios autônomos, com governo próprio - os 'estados', que se unem para constituir a federação/ o país. São 26 estados e o Distrito Federal - Brasília), e Brasil (Pau Brasil - árvore nativa da Mata Atlântica, abundante na época do descobrimento). Ela me pediu imagens da árvore Pau Brasil, então enviei-lhe um e-mail (Carla- trecho de postagem em portfólio virtual). 
c) Não se discute muito sobre a gramática normativa (tanto de PLE e de ELE) embora haja ocorrências de pedido de explicação: [...] citei a reforma ortográfica brasileira, como ela ficou interessada, e me fez perguntas que ainda não estava muito interada (rsrsrsrs), passei-lhe um site de onde ela poderia baixar as normas [...] [ela] me disse que lá estão passando por uma psicoses sobre o assunto_ Psicoses que, com o novo acordo ortográfico Uruguaio, não se escreve mais com $\mathrm{P}$ (que já não era pronunciada)hoje se escreve Sicoses (Carla- trecho de postagem em portfólio virtual).

d) Os docentes não dissociam língua/cultura, mas reconhecem a complexidade do tema e a necessidade de ampliar seus conhecimentos sobre o Brasil:

Acredito que a interculturalidade não se dá somente entre povos que falam línguas diferentes, mas, como no caso do Brasil, a interculturalidade ocorre entre povos de diferentes regiões. As discrepâncias lexicais e fonéticas, sem falar de todos costumes diversos da população sulista de nosso país é um exemplo da interculturalidade existente.Antes do teleduc, não havia tido contatos interculturais com pessoas que não tivessem o português como língua materna. Entretanto, tive contato com pessoas de outras regiões do Brasil, fatos bastante interessantes e geralmente cômicos...por exemplo, uma amiga gaucha de minha mãe veio visitá-la em (nome de um município no interior paulista), e ao chegar em casa, estava com um péssimo humor. O que havia acontecido, é que no caminho a mulher decidiu levar pães para que tomássemos café todos juntos, e não conseguiu comprá-los, já que pediu para uma senhora idosa que trabalhava na padaria cinco cacetes...a senhora simplesmente fechou as portas do seu comércio, e falou que aquele ambiente era um lugar de respeito...rsrsrs (Penélope - trecho de postagem em portfólio virtual). 
e) Os docentes brasileiros acreditam que deva haver particularidades quanto ao ensino de PLE, embora afirmem que a base teórica do ensino de LE dê sustentação à práxis do professor:

Ao construir um novo conhecimento relacionado a uma "nova língua" e toda sua cultura relacionada, passei a ampliar minhas concepções de mundo, de ser brasileiro, isso faz com que transforme minhas percepções sobre a sociedade e vida (Penélope - trecho de postagem em portfólio virtual).

Observamos durante o período desse estudo que os professores possuem a consciência de que o trabalho docente assume uma dinâmica de permanente renovação, sendo um trabalho intelectual por essência e que apesar de estarem em constante busca por aprimoramento, ainda assim podem se deparar com uma realidade nova ao integrar em curso de aprendizagem de línguas em meio midiático, conforme expressa Gesebel:

Continuar estudando, a meu ver, é uma atividade inerente ao professor. [...] explicito isso tudo aqui para pontuar a importância que o TTB teve na minha formação profissional. Encerro esse curso com uma sensação de que sou professora de duas línguas estrangeiras: espanhola e portuguesa (Gesebel - trecho de postagem em portfólio virtual).

Verificamos também que o curso tornou-se importante sob o ponto de vista do ensino de língua portuguesa como língua estrangeira (isso, num contexto específico de ensino/ aprendizagem de idiomas, por ser mediado por computador e seguir determinados critérios de interação entre pares como é o teletandem). Os participantes demonstraram-se motivados ao vivenciarem sua própria língua e cultura a partir da concepção do "outro".

No estudo apresentado, a consciência linguística de ambos os interagentes é ressaltada pelos pares brasileiros como facilitador do ensino de PLE. As representações dos professores sobre o ensino de PLE demonstram o despreparo, mas também o despertar para mais uma possibilidade no ensino de línguas. 
Em relação ao meio midiático, averiguou-se que o nível de letramento digital no grupo era heterogêneo. Entretanto, os participantes expunham suas dúvidas e seus "medos" em relação ao manuseio das ferramentas utilizadas nas sessões de teletandem. Assim sendo, como parte do desenho do curso, os professores colaboradores tiveram uma aula prática em laboratórios tecnológicos em duas universidades do interior paulista concomitantemente. Além disso, contavam com o apoio presencial dos formadores para maiores esclarecimentos quanto ao uso das ferramentas mediante agendamento. A primeira sessão de bate-papo ocorreu sobre o uso das ferramentas para a gravação das sessões de teletandem, uma vez que alguns participantes ainda apresentavam dificuldades na configuração. $\mathrm{Na}$ segunda sessão ainda notamos ocorrências de esclarecimentos sobre os aplicativos, mas nenhuma outra ocorrência após esta. Vejamos alguns excertos ilustrativos:

Estou aqui, olhando muito atenta tudo,a tecnología asusta um poquinho... porque as veces que a gente tem "medos" mas agora estou intentando sacar fora (Mariella - sessão de bate-papo 1).

Acho que as pessoas deveriam trazer a tecnologia pras suas vidas, fazer dela algo rotineiro, diário, assim como assistir tv, o computador, a internet, enfim, essa tecnologias são ferramentes imprescindíveis na vida do homem moderno e por que muitos professores ainda ressistem à elas...? (Juán - sessão de bate-papo 2).

Ao debater sobre as novas tecnologias aplicadas ao ensino de línguas, observamos que os professores consideram essencial encontrar um "modo" de mudar as relações entre professor-aluno, mas que isso não é fácil. A seguir listamos as considerações levantadas em relação à ajuda pedagógica em meio virtual:
a) o favorecimento da autonomia dos alunos;
b) a mudança nas relações entre o docente e o discente;
c) o despertar da curiosidade; 

d) a diminuição de "distâncias";
e) a promoção da criatividade.

Percebemos que o movimento de "naturalização" das tecnologias digitais (TDs) ganha o efeito de "necessidade" entre os participantes de pesquisa e que cria no imaginário desses professores uma situação de conflito, pois nos perguntamos como "controlar" o que é feito em contexto teletandem, uma vez que a inovação desse modo de aprendizagem de LE traz à superfície o desconhecimento em detrimento daquele que exerce o poder legitimado pelo saber.

\section{Considerações finais}

As informações apresentadas neste trabalho são reflexões preliminares, um ensaio, pois o papel do professor na fase atual das TDs precisa ser colocado dentro de uma perspectiva acadêmica mais adequada, seja por meio de uma melhor compreensão de sua origem epistemológica de base complexa, seja também pela maior conscientização de sua formação específica que englobe a educação centrada no sujeito social, no autoconhecimento e reconhecimento do outro e em uma visão ecológica de ensino interativo e interdependente.

Quanto às representações sociais dos professores, observamos duas relações distintas que surgiram especificamente em relação ao ensino de PLE: cultura na língua, que pressupõe o ensino de aspectos culturais simultaneamente ao trabalho com a aquisição da língua, sem haver, entretanto, nenhum tipo de reflexão intercultural durante as interações e língua como cultura, que prevê a reflexão/comparação, durante o trabalho com o sistema formal, sobre aspectos culturais de outros países e sua relação com a cultura nacional - a transculturalidade (KRAMSCH,1996, p. 7).

Quanto às representações dos professores em relação ao ensino de PLE, nesse estudo observamos que: (a) a experiência de ensinar sua própria língua materna como língua estrangeira proporcionou reflexões sobre 
uma práxis diferenciada, uma vez que sua fundamentação é questionada, assumindo-se como saber consciente, não apenas intuitivo, ocasionando possíveis rupturas e renovações; (b) segundo os dados coletados, ensinar uma língua estrangeira, especificamente o português, é uma forma de se estar em contato com diferentes culturas e pessoas, trocando informações, aprendendo coisas novas, bem como aprofundar os conhecimentos acerca da própria língua e do seu modo de vida; (c) entender sua língua e mundo sob a ótica do outro propiciam reflexões e buscas sobre os estereótipos que os professores possuem sobre sua própria cultura e sobre a cultura do outro; (d) ensinar PLE é complexo, pois uma vez que não se recebe instrução formal, as tentativas de ensino ocorrem de modo intuitivo.

Consideramos que os aspectos abordados neste artigo, objetivam a um delineamento das concepções epistemológicas do professor quanto ao ensino em meio virtual e quanto ao Português Língua Estrangeira, e que necessitam ser aprofundados de forma específica. Ao vislumbrarmos o crescente interesse pela aprendizagem de PLE, deparamo-nos com as questões acima explicitadas além de interesses pluridimensionais que vão desde a formação específica de professores, perpassando pelas atitudes de curiosidade, ponderação sobre as diferenças e de desprendimento para a aceitação de outras culturas e para uma percepção de sua própria cultura sob outra perspectiva. Desse modo, vislumbramos também a necessidade do debate a respeito da transculturalidade (WELSCH, 1994) e dos saberes que valorizem a compreensão da relação cultura/identidade em ambientes de ensino e aprendizagem virtuais tão complexos como o teletandem.

\section{Referências}

BELZ, Julie. A.; MÜLLER-HARTMANN, Andreas. Teachers as intercultural learners: negotiating German-American Telecollaboration along the institutional faultline. The Modern Language Journal, v. 87, n. 1, p. 71-89, 2003. 
BYRAM, Mike. Teaching and assessing intercultural communicative competence. Clevedon: Multilingual Matters, 1997.

CARVALHO, Ana. M. Eu falo como na televisão: palatalização e urbanização em português uruguaio. In: ESPIGA, Jorge; ELIZACIN, Adolfo (Eds.). Español y Português: fronteiras e contatos. Pelotas: Universidade Católica de Pelotas, 2008. p. 65-105.

. Variation and diffusion of Uruguayan Portuguese in a bilingual border town. In: CABEZA, Carmen; RODRÍGUEZ, Yáñez; SUÁREZ, Lorenzo (Eds.). Comunidades e individuos bilingues. Actas do I Simpósio Internacional sobre o Bilinguismo. Vigo: Universidade, 2003. p. 642-651. Disponível em: <http://webs.uvigo.es/ss1/actas1997/05/Carvalho.pdf〉. Acesso em: 16 out 2011.

FAIRCLOUGH, Norman. The appropriacy of "appropriateness". In: FAIRCLOUGH, Norman. (Ed.). Critical language awareness. London: Routledge, 1992.

FUNO, Ludmila B. A. Teletandem e formação contínua de professores vinculados à rede pública de ensino do interior paulista: um estudo de caso. 2011. 195 f. Dissertação (Mestrado em Estudos Linguísticos) - Instituto de Biociências Letras e Ciências Exatas da Universidade Estadual Paulista, São José do Rio Preto, 2011.

GEYMONAT, Javier; BRIAN, Nicolás; BROVETTO, Cláudia. (Eds). Portugués del Uruguay y educación bilingüe. Montevideo: Administración Nacional de Educación Pública, 2007. p. 44-96.

GOFFMAN, Erving. Estigma: notas sobre a manipulação da identidade deteriorada. Rio de Janeiro: LTC, 1988.

JODELET, Denise. Représentation sociale: phénomene, concept et théorie. In: MOSCOVICI, Serge. (Ed.) Psychologie sociale. 2. ed. Paris: Presses Universitaires de France, 1990.

KERN, Robert; WARE, Paige; WARSCHAUER, Mark. J. Crossing frontiers: new directions in online pedagogy and research. Annual Review of Applied Linguistics, v. 24, n. 1, p. 243-260, 2006. 
KRAMSCH, Claire. Zeitschrift für Interkulturellen Fremdsprachenunterricht. The cultural component of language teaching. v. 1, n. 2, p. 13, 1996. Disponível em: <http://www.spz.tudarmstadt.de/projekt_ejournal/jg_01_2/beitrag/ kramsch2.htm>. Acesso em: 21 fev 2010.

LUZ, Emeli B. P. A autonomia no processo de ensino e aprendizagem de linguas em ambiente virtual (teletandem). 2009. 230 f. Dissertação (Mestrado em Estudos Linguísticos) - Instituto de Biociências Letras e Ciências Exatas da Universidade Estadual Paulista, São José do Rio Preto, 2009.

MOSCOVICI, Serge. Representações sociais: investigação em psicologia social. Petrópolis: Vozes, 2007.

O'DOWD, Robert. Understanding the "other side": intercultural learning in a Spanish-English e-mail exchange. Language Learning E Technology, v. 7, n. 2, p. 118-144, 2003. Disponível em: http://llt.msu.edu/vol7num2/ odowd/default.html. Acesso em: 22 jun 2008.

O'REILLY, Tim. What is Web 2.0: design patterns and business models for the next generation of software . Communications and Strategies, n. 65, 2007.

ORTÍZ ALVAREZ, Maria Luiza; SANTOS, Percília. Aspectos culturais relevantes no ensino de português para falantes de espanhol: as expressões idiomáticas e a carga cultural compartilhada. In: SANTOS, Percília; ORTÍZ ALVAREZ, Maria. Luiza. (Orgs.) Lingua e cultura no contexto de português língua estrangeira. Campinas: Pontes Editores, 2010.

REVUZ, Christine. A língua estrangeira entre o desejo de um outro lugar e o risco do exílio. In: SIGNORINI, Inês. (Org.). Lingua (gem) e identidade: elementos para uma discussão no campo aplicado. Campinas: Mercado das Letras; São Paulo: Fapesp, 1998. p. 213-230.

SALOMÃO, Ana Cristina B. Gerenciamento e estratégias pedagógicas na mediação dos pares no teletandem e seus reflexos para as práticas pedagógicas dos interagentes. 2008. 317 f. Dissertação. (Mestrado em Estudos Linguísticos) - Instituto de Biociências Letras e Ciências Exatas da Universidade Estadual Paulista, UNESP, São José do Rio Preto, 2008. 
SOUZA, Regina M.; CARVALHO, Alexandre F. O que ou quem eu sou, afinal de contas? Sou brasileiro ou uruguaio, professor? Revista Próposições, v. 21; n. 3, p. 45-65. 2010. Edição especial: Educação fronteiriça Brasil/Uruguai: línguas e sujeitos. Campinas: Unicamp, 2010. Disponível em: <http://mail.fae.unicamp.br/ proposicoes/edicoes/sumario62.html>. Acesso em: 03 dez 2010.

TELLES,João A.Teletandem: metamorfoses impostas pela tecnologia sobre o ensino de línguas estrangeiras. In: TELLES, João A. (Org.). Teletandem: um contexto virtual, autônomo e colaborativo para aprendizagem de línguas estrangeiras no século XXI. Campinas: Pontes Editores, 2009.

THORNE, Steve L.; PAYNE, J. Scott. Evolutionary trajectories, internetmediated expression, and language education. Disponível em: <http:// language.la.psu.edu/ thorne/thorne_payne_calico2005.pdf $>$. Acesso em: 08 fev 2011.

VAN MANEN, Max. Researching lived experience. London, Ontario: The Althouse Press, 1990.

VASSALLO, Maria Luiza; TELLES, João A. Foreign language learning in-tandem: theoretical principles and research perspectives. The ESPecialist, v. 25 , n. 1, p.1-37, 2006.

- Aprendendo línguas estrangeiras in-tandem: histórias de identidades. Revista Brasileira de Linguistica Aplicada. Disponível em: <http://www.letras.ufmg.br/rbla/revista2008_2.html>. Acesso em: $14 \mathrm{fev}$ 2009.

WELSCH, Wolfganf. Transculturality: the puzzling forms of culture today. California Sociologist Journal, v. 17, n. 18, p. 19-39, 1994. 